Open Access

\title{
Agreement of Turkish Physiatrists with the Assessment in Spondyloarthritis International Society and the European League Against Rheumatism Recommendations for the Management of Ankylosing Spondylitis and Rheumatoid Arthritis
}

\author{
Salih Ozgocmen *, , Ozgur Akgul ${ }^{1}$, Aysen Akınc1², Sebnem Ataman ${ }^{3}$, Murat Birtane ${ }^{4}$, Hatice Bodur ${ }^{5}$, \\ Rezan Günaydın ${ }^{6}$, Ömer Kuru ${ }^{7}$, Aylin Rezvani ${ }^{8}$, Omer Faruk Şendur ${ }^{9}$, Kazım Şenel ${ }^{10}$ and Tiraje Tuncer ${ }^{11}$ \\ ${ }^{I}$ Division of Rheumatology, Department of PMR, Erciyes University, Faculty of Medicine, Gevher Nesibe Hospital, \\ Kayseri Turkey \\ ${ }^{2}$ Department of PMR, Hacettepe University, Faculty of Medicine, Ankara, Turkey \\ ${ }^{3}$ Division of Rheumatology, Department of PMR, Ankara University, Faculty of Medicine, Ankara, Turkey \\ ${ }^{4}$ Department of PMR, Trakya University, Faculty of Medicine, Edirne, Turkey \\ ${ }^{5}$ Physical Medicine and Rehabilitation Clinic, Ankara Numune Training and Research Hospital, Ankara, Turkey \\ ${ }^{6}$ Physical Medicine and Rehabilitation Clinic, Izmir Bozyaka Training and Research Hospital, Izmir, Turkey \\ ${ }^{7}$ Department of PMR, Ondokuzmayis University, Faculty of Medicine, Samsun, Turkey \\ ${ }^{8}$ Department of PMR, Bezmialem Vakif University, Faculty of Medicine, Istanbul, Turkey \\ ${ }^{9}$ Department of PMR, Adnan Menderes University, Faculty of Medicine, Aydin, Turkey \\ ${ }^{10}$ Department of PMR, Ataturk University, Faculty of Medicine, Erzurum, Turkey \\ ${ }^{11}$ Division of Rheumatology, Department of PMR, Akdeniz University, Faculty of Medicine, Antalya, Turkey
}

\begin{abstract}
Background: New developments in the field of targeted therapies or biologic agents led more effective management of ankylosing spondylitis (AS) and rheumatoid arthritis (RA). Recommendations for the management of rheumatic diseases propose to reduce inappropriate use of medications, minimize variations among countries, and enable cost-effective use of health care resources.

Objective: The aim this study was to evaluate conceptual agreement of ASsessment in SpondyloArthritis International Society (ASAS) and the EUropean League Against Rheumatism (EULAR) recommendations for the management of AS and EULAR recommendations for RA and to assess the rate of application among Turkish physiatrists in daily clinical practice.

Methods: An online survey link has been sent to 1756 Turkish physiatrists with e-mails asking to rate agreement on 11item ASAS/EULAR AS recommendations and 15-item EULAR RA recommendations with synthetic and biological disease-modifying anti-rheumatic drugs. Also barriers and difficulties for using biologic agents were assessed.

Results: Three hundred nine physiatrists (17.5\%) completed the survey. The conceptual agreement with both recommendations was very high (Level of agreement; mean $8.35 \pm 0.82$ and $8.90 \pm 0.67$ for RA and AS recommendations, respectively), and the self-declared application of overall recommendations in the clinical practice was also high for both RA and AS (72.42\% and $75.71 \%$, respectively).

Conclusion: Turkish physiatrists are in good conceptual agreement with the evidence-based recommendations for the management of AS and RA. These efforts may serve to disseminate the knowledge and increase the current awareness among physicians who serve to these patients and also implementation of these recommendations is expected to increase as well.
\end{abstract}

Keywords: Rheumatoid arthritis, ankylosing spondylitis, recommendations, agreement, physiatrist.

*Address correspondence to this author at the Division of Rheumatology, Erciyes University, Gevher Nesibe Hospital, 38039, Kayseri Turkey; Tel: 0090352 4374901; Fax: 0090352 2353605;

E-mail: sozgocmen@hotmail.com

\section{INTRODUCTION}

New pivotal innovations in the field of targeted therapies or namely treatment with biological agents led more effective management of spondyloarthropathies ( $\mathrm{SpA})$ including ankylosing spondylitis (AS) and rheumatoid 
arthritis (RA). With these rapid developments in the field, many experts or officially representative groups proposed recommendations or guidelines for the management of rheumatic diseases. These novel therapies are reasonably expensive and potentially have side effects which further require standardization in their use. Recommendations for the management or treatment of rheumatic diseases, whether at international or national level, propose to reduce inappropriate use of these medications, minimize variations from country to country, and enable cost-effective use of health care resources.

In 2006 ASsessment in SpondyloArthritis International Society (ASAS) and the EUropean League Against Rheumatism (EULAR) published recommendations for the management of AS which were developed based on evidence and expert opinion [1]. Evaluation of these recommendations by a large number of rheumatologists from 10 countries revealed high degree of conceptual agreement [2]. Furthermore ASAS group pointed out the necessity of dissemination and evaluation of these recommendations among patients with AS. Kiltz et al., first developed patient version of these recommendations with an international collaboration of English speaking patients [3] and then German [4] and Turkish translation [5] of the patient versions have been published. Also some of the countries have developed their own recommendations or assessed the conceptual agreement with these recommendations at national level [6-8]. Recently ASAS/EULAR recommendations for the management of AS have been updated [9].

Therapeutic strategies in RA have undergone dramatic changes during the past decade. Novel therapies other than synthetic disease modifying anti-rheumatic drugs (DMARDs) have been introduced. These biologic agents, which target tumor necrosis factor (TNF), the interleukin 1 (IL-1) receptor, the IL-6 receptor, B lymphocytes and T-cell costimulation, are highly effective. These rapid and tremendous changes in targeted therapies as well as strategies for initiation and follow up of early disease overwhelmed physicians and patients. In a recent survey, which was applied during EULAR Congress, inconsistencies in therapeutic targets and treatment strategies among rheumatologists have been recognized [10]. These discrepancies may strongly be related to the fact that reimbursement strategies and patients and physicians perspectives change from country to country. In order to "find a consensus on recommendations" for the management of RA with synthetic and biological DMARDs, EULAR initiated the project and recent recommendations have been published [11].

Turkish physiatrists and rheumatologists are actively involved in both pharmacological and non-pharmacological treatment of AS and RA. Biologic agents including TNF inhibitors could be prescribed by physiatrists as well as rheumatologists in accordance with national guidelines. Turkish League Against Rheumatism (TLAR) was founded in 1947 by Turkish physiatrists and acts as the official representative of Turkey in EULAR since 1947. In 2010 and 2011, TLAR initiated a series of activities including targeted lectures in National Congresses and Symposiums of Rheumatic Diseases, reviews to be published in national medical journals to increase the current awareness on these recommendations. Recently, a project to adopt and built up national recommendations for the management of AS and RA was initiated by TLAR in order to better disseminate and share the knowledge of these recommendations $[6,12]$. In many countries, rheumatologists are the specialists who are primarily responsible for the management of RA. Physical Medicine and rehabilitation specialists (physiatrists) have been primarily responsible for treating rheumatic diseases for a very long time in Turkey. This responsibility comes from the regulatory laws (May 8th, 1929, No.1219 on the Practice of the Art of Medicine and its Branches) which shaped the legal framework of modern medicine in Turkey. Rheumatology divisions were then founded within the departments of PMR and Internal Medicine with the approval of both Ministry of Health and Council of Higher Education and sub-specialty programs continues since 1986 [12]. Now the number of rheumatologist originated from PMR or internal medicine is nearly 200 which is still nearly $10 \%$ of the total number of physiatrists.

The objective of this study was to evaluate conceptual agreement and rate of application of recommendations for the management of AS and RA in daily clinical practice among Turkish physiatrists.

\section{METHODS}

This project was initiated by a group of Turkish physiatrists in collaboration with Turkish League Against Rheumatism (TLAR). A questionnaire was developed by the group consisting number of years in clinical practice, affiliations, mean number of patients with AS or RA seen in a week, and barriers or difficulties for the use of biologic agents. The updated 11-item ASAS/EULAR recommendations for the management of AS [9] and 15-item EULAR recommendations for the management of RA with synthetic and biological disease-modifying anti-rheumatic drugs [9] have been translated into Turkish. The group collectively validated the accuracy and fluency of the translated text item by item. An 11-point Liekert scale was used to assess conceptual agreement; 0, indicated absolute disagreement, and 10, indicated absolute agreement. The survey was tagged into three pages; first, general information related to the self experience, affiliations, number of patients, barriers or difficulties for the use of biologic agents; second, conceptual agreement on EULAR recommendations for the management of RA; third, conceptual agreement on ASAS/EULAR recommendations for the management of AS.

The last two questions in the second and third "agreement" pages were "Regarding the recommendations of ASAS/EULAR for the management of AS, could you please give ratio of the overall application of these recommendations in your daily clinical practice while treating patients with AS?" and "Regarding overall recommendations of EULAR for the management of RA with synthetic and biological disease-modifying antirheumatic drugs, could you please give ratio of the overall application of these recommendations in your daily clinical practice while treating patients with RA?". These questions were self rated by the participant changing from 0 to $100 \%$.

The questionnaire was built up and surveyed through a commercial website which send and collect answers on-line and analyze as well. Electronic mail addresses were obtained 
from two official e-mail platforms of the societies. Mail lists contained only specialists in the field of physical medicine and rehabilitation and fellows in training were excluded. Links for the survey page were submitted through internet and all were case sensitive. All participants were allowed for one month to complete the survey and reminders were sent regularly every week. Also an invitation letter to participate in this survey and weekly announcements were submitted through the official e-mail platforms (E mail lists of Turkish League Against Rheumatism and Turkish Society of Physical Medicine and Rehabilitation).

Results were obtained from the website as excel sheets and transferred into Statistical Package for Social Sciences (SPSS) software. Results for the agreement were calculated as mean and standard deviations and demographic variables as cross-tabulation where appropriate. Pearson correlation analysis was used to assess relationship between number of patients and level of agreement. A p value less than 0.05 was accepted as statistically significant.

\section{RESULTS}

The survey link was sent to 1756 e-mail addresses and allowed for 30 days to fill. Every week a reminder was sent by the system if the participants has not accepted or completed the online forms. Accordingly an e mail invitation was sent to the official e-mail lists asking for participation in the survey and requesting to screen junk e-mail folders for possible drop outs.

At the end of one month, 309 physiatrists (17.5\%) completed the survey. All 309 were physiatrists and 16 had also sub-specialty in rheumatology (certified rheumatologist) and 7 had PhD degree.

\section{Conceptual Agreement of EULAR Recommendations for the Management of Rheumatoid Arthritis}

The general characteristics of the participants completed questionnaire for RA are given in Table 1. Conceptual agreements on the items of the recommendations for the management of RA are given in Table 2. In Turkey, a great majority of the specialists who primarily care for the patients with AS and RA are physiatrists. In order to prevent biased ratings we separated only the first sentence of the overarching principles in which "rheumatologists" are underlined as the physicians who "should primarily care for patients with RA". Indeed the agreement on this sole sentence was very poor $(2.86 \pm 3.17)$. Nearly all of the items passed with an agreement score more than 7.0 except item-5. In this item Turkish physiatrist less agree that "in DMARD naïve patients, irrespective of the addition of GCs, synthetic DMARD monotherapy rather than combination therapy of synthetic DMARDs may be applied". The self-reported application of overall recommendations in daily clinical practice was nearly $72 \%$, which was quite satisfactory.

\section{Agreement of EULAR Recommendations for the Management of Ankylosing Spondylitis}

The general characteristics of the participants completed questionnaire for AS are given in Table 3. Agreements on the items of the recommendations for the management of AS are given in Table 4. Irrespective of RA recommendations,
ASAS/EULAR prefer to use "coordinated by the rheumatologist" which is welcomed by other physicians dealing with AS so we left this item as is in the survey.

Table 1. General Characteristic of the Physiatrist Completed the Pages Related to RA $(n=295)$

\begin{tabular}{|l|c|}
\hline \multicolumn{1}{|c|}{ Characteristics } & Mean (SD) or Ratio \\
\hline \hline Years in practice, mean (SD) & $10.92(7.68)$ \\
\hline Number of patients with RA in a week, mean (SD) & $7.72(8.73)$ \\
\hline $\begin{array}{l}\text { Tertiary centers } \\
\text { (University hospitals), \% }\end{array}$ & 35.3 \\
\hline $\begin{array}{l}\text { Tertiary centers } \\
\text { (Research and training hospitals), \% }\end{array}$ & 15.9 \\
\hline $\begin{array}{l}\text { Tertiary centers } \\
\text { (Rehabilitation research and training centers), \% }\end{array}$ & 2.7 \\
\hline $\begin{array}{l}\text { Secondary centers } \\
\text { (State hospitals, rehabilitation centers), \% }\end{array}$ & 19 \\
\hline $\begin{array}{l}\text { Secondary centers } \\
\text { (Military hospitals), \% }\end{array}$ & 2.4 \\
\hline $\begin{array}{l}\text { Secondary Centers } \\
\text { (Affiliated out-patient clinics), \% }\end{array}$ & 0.7 \\
\hline Private hospitals, $\%$ & 14.2 \\
\hline Private physiotherapy and rehabilitation centers, \% & 7.5 \\
\hline Private practice or retired & 2.3 \\
\hline
\end{tabular}

Table 2. Conceptual Agreement and Self Reported Overall Application of EULAR Recommendations for the Management of RA

\begin{tabular}{|l|c|c|}
\hline \multicolumn{1}{|c|}{ Item } & Mean & SD \\
\hline \hline Overarching principles & 7.23 & 3.04 \\
\hline Item-1 (starting DMARDs early) & 8.62 & 2.60 \\
\hline Item-2 (remission-monitoring) & 9.49 & 1.44 \\
\hline Item-3 (Methotrexate) & 9.05 & 2.05 \\
\hline Item-4 (DMARDs other than MTX) & 7.99 & 2.21 \\
\hline Item-5 (Monotherapy rather than combination) & 6.28 & 3.09 \\
\hline Item-6 (Adding GCs) & 8.86 & 2.10 \\
\hline Item-7 (Biologics when poor prognosis) & 8.55 & 2.02 \\
\hline Item-8 (responding insufficiently, start TNF inhibitors) & 8.67 & 1.98 \\
\hline $\begin{array}{l}\text { Item-9 (Failure in first TNF inhibitor, } \\
\text { start another TNF inhibitor or other biologics) }\end{array}$ & 8.22 & 2.25 \\
\hline $\begin{array}{l}\text { Item-10 (Refractory severe RA or biologics } \\
\text { contraindicated other synthetic DMARDs ) }\end{array}$ & 7.87 & 2.24 \\
\hline Item-11 (Intensive medication strategies) & 8.80 & 1.87 \\
\hline Item-12 (Persistent remission tapering of biologics) & 8.15 & 2.29 \\
\hline $\begin{array}{l}\text { Item-13 (Sustained long-term remission, cautious } \\
\text { titration of synthetic DMARD) }\end{array}$ & 8.73 & 1.86 \\
\hline $\begin{array}{l}\text { Item-14 (Poor prognostic factors combination } \\
\text { of MTX with a biologic) }\end{array}$ & 7.68 & 2.76 \\
\hline $\begin{array}{l}\text { Item-15 (progression of structural damage, } \\
\text { comorbidities and safety concerns) }\end{array}$ & 9.41 & 1.42 \\
\hline Self-declared application of overall recommendations, \% & 72.42 & 20.53 \\
\hline
\end{tabular}


Table 3. General Characteristic of the Physiatrist Completed the Pages Related to AS $(n=275)$

\begin{tabular}{|l|c|}
\hline \multicolumn{1}{|c|}{ Characteristics } & $\begin{array}{c}\text { Mean (SD) } \\
\text { or Ratio }\end{array}$ \\
\hline \hline Years in practice, mean (SD) & $11.13(7.78)$ \\
\hline Number of patients with AS in a week, mean (SD) & $5.80(6.65)$ \\
\hline Tertiary centers (University hospitals), \% & 36.7 \\
\hline Tertiary centers (Research and training hospitals), $\%$ & 15.6 \\
\hline $\begin{array}{l}\text { Tertiary centers } \\
\text { (Rehabilitation research and training centers), } \%\end{array}$ & 2.9 \\
\hline $\begin{array}{l}\text { Secondary centers } \\
\text { (State hospitals, rehabilitation centers), } \%\end{array}$ & 18.9 \\
\hline Secondary centers (Military hospitals), $\%$ & 2.45 \\
\hline Secondary Centers (Affiliated out-patient clinics), $\%$ & 0.7 \\
\hline Private hospitals, $\%$ & 13.5 \\
\hline Private Physiotherapy and rehabilitation centers, $\%$ & 6.9 \\
\hline Private practice or retired & 2.2 \\
\hline
\end{tabular}

Table 4. Conceptual Agreement and Self Reported Overall Application of ASAS/EULAR Recommendations for the Management of AS

\begin{tabular}{|l|c|c|}
\hline \multicolumn{1}{|c|}{ Item } & Mean & SD \\
\hline \hline Overarching principles & 8.24 & 2.61 \\
\hline Item-1 (General treatment) & 9.50 & 1.30 \\
\hline Item-2 (Disease monitoring) & 9.26 & 1.42 \\
\hline Item-3 (Non-pharmacological treatment) & 9.60 & 1.19 \\
\hline $\begin{array}{l}\text { Item-4 } \\
\text { (Extra-articular manifestations and co-morbidities) }\end{array}$ & 9.52 & 1.26 \\
\hline Item-5 (Non-steroidal anti-inflammatory drugs) & 9.52 & 1.24 \\
\hline Item-6 (Analgesics) & 7.89 & 2.80 \\
\hline Item-7 (Glucocorticoids) & 8.97 & 1.90 \\
\hline Item-8 (Disease-modifying anti-rheumatic drugs) & 7.85 & 2.76 \\
\hline Item-9 (Anti TNF therapy) & 8.59 & 2.13 \\
\hline Item-10 (Surgey ) & 8.38 & 2.19 \\
\hline $\begin{array}{l}\text { Item-11 } \\
\text { (Changes in the disease course) }\end{array}$ & 9.50 & 1.19 \\
\hline $\begin{array}{l}\text { Self-declared application of } \\
\text { overall recommendations, \% }\end{array}$ & 75.71 & 21.20 \\
\hline
\end{tabular}

Nearly all of the items passed with an agreement score more than 7.0. Relatively lesser agreement was obtained in analgesics and DMARD use in AS. The self-reported application of these recommendations in daily clinical practice was nearly $76 \%$ which is quite satisfactory.

\section{Barriers and Difficulties in the Management}

Biologic agents in the management of RA and AS are available in Turkey and reimbursement strategies are regulated by national bylaws. Physiatrists have the right to prescribe these medications for the treatment of AS and RA as well. We asked to tick at least one (up to three most important) of the predefined barriers or difficulties which physiatrists most frequently confronted. These barriers or difficulties are itemed by the group and the most frequently ticked items in the use of biologics for the management of RA or AS are shown in the Table 5.

Table 5. Most Frequently Declared Barriers or Difficulties Confronted During the Management of RA or AS Using Biologic Agents

\begin{tabular}{|l|c|c|}
\hline \multicolumn{1}{|c|}{ Barriers or Difficulties } & n & \% \\
\hline \hline No difficulty or barrier & 43 & 14 \\
\hline Necessity for approval of other physicians & 112 & 36 \\
\hline Long time for reporting/prescribing formalities & 102 & 33 \\
\hline Difficulties to follow up serious side effects & 69 & 22 \\
\hline Difficulties in the drug administration & 50 & 16 \\
\hline Higher costs and load to the insurance system & 36 & 12 \\
\hline $\begin{array}{l}\text { Patients unwillingness to undersign predefined } \\
\text { statements and consents }\end{array}$ & 25 & 8 \\
\hline $\begin{array}{l}\text { Personal or institutional discouraging experiences } \\
\text { in the past }\end{array}$ & 4 & 1 \\
\hline Other causes & 70 & 23 \\
\hline
\end{tabular}

The rate of application in the routine clinical practice was correlated with the weekly number of patients seen (for AS recommendations $r=0.23$ and for RA recommendations $r=0.20$, $\mathrm{p}<0.0001)$.

\section{DISCUSSION}

The results from the survey revealed that conceptual agreement with both recommendations was very high (Level of agreement; mean $8.35 \pm 0.82$ and $8.90 \pm 0.67$ for RA and AS recommendations, respectively), and the self-declared application of overall recommendations in the clinical practice was also high for both RA and AS (72.42\% and $75.71 \%$, respectively). Additionally, to the best of our knowledge, this survey is probably the first to evaluate agreement or application among physicians (great majority of physiatrists) other than rheumatologists dealing with rheumatic diseases.

In recommendations for the management of RA, Turkish physiatrists are in good agreement with the majority of the recommendations except the item-5. In this item the approach to the management of a DMARD naïve patient, irrespectively with additional GCs, may be the monotherapy with synthetic DMA $\mathrm{RD}$ rather than combination therapy of synthetic DMARDs. Although the authors of the EULAR recommendations stated that there is not robust evidence for the general superiority of DMARD combinations in comparison with respective monotherapies, additional GC may cause some compelling results [11]. This may be the effect of slightly reduced rating of this item by the physiatrists. Agreement on the recommendations for the management of AS was slightly higher. Nearly all of the items of ASAS/EULAR recommendations are welcomed by the Turkish physiatrists. The third item related to the non-pharmacological management of AS had the highest agreement score (9.60). This agreement is especially important 
for the fact that Turkish physiatrists actively involved in the physiotherapy and rehabilitation process of the patients with AS and have vast experience in this field. Unlike some of the western countries, costs of the physiotherapy and rehabilitation are completely reimbursed by the insurance system if prescribed and conducted by the physiatrists. Regarding the whole score of agreement, our results are in accordance with the previous survey evaluating these recommendations among rheumatologists from different countries not including Turkey [2]. The mean \pm SD score obtained in that study was $8.90 \pm 0.9$ which is quite similar to ours $(8.90 \pm 0.67)$, revealing that Turkish physiatrists share same thoughts with rheumatologists from different countries.

In our survey we prefer to use the self-rating of the overall recommendations in daily practice rather than rating all the items individually. Some of the drugs stated in the items are not reimbursed if not applied in the tertiary centers (i.e. some of the biologics) so the physicians from secondary centers would fail to score applicability of these items. Therefore we thought that rating the whole items together would be much more feasible. Indeed the overall rate of self-reported application was plausibly good for both recommendations $(>70 \%)$.

In this survey barriers or difficulties in the treatment of RA or AS using biologic agents were assessed. Only $14 \%$ of participants noted no difficulty and the rest of participants ticked at least one of the pre-defined barriers or difficulties. Prescribing and application rules for the use of biologic agents in the treatment of rheumatic diseases are defined by the drug commissions of Ministry of Health and the costs are reimbursed by the national social security system in terms of bylaws. It is necessary to document the screening of tuberculosis and malignancies with joint report undersigned by the referring physician (a physiatrist or a rheumatologist), an internist and a chest physician. The participants underlined the most frequently confronted barriers or difficulties as the necessity for approval of other physicians, long time for reporting/prescribing formalities and safety concerns. Previous survey on ASAS/EULAR recommendations for AS also underscores similar barriers, such as national limitations to prescribe these expensive drugs or a general lack of adequate resources and/or poor infrastructure [2].

This survey study has some limitations, like relatively low response rate. The allowed time period (one month) for filling the survey might not be long enough and the survey pages may be relatively long that contains too much items for both RA and AS recommendations. Some of the participants might have been inevitably bored filling this long survey. We think that some of the non-responders, particularly those in specific rehabilitation centers who are not frequently treating patients with RA and AS, did not fill the survey. There may be also other technical factors like undesired filtering of the survey link mails by the junk mail filters or etc which further increased the drop outs. These technical factors will be probably overcome by the new software or other technological innovations.
As a consequence, Turkish physiatrists are in good conceptual agreement with the evidence-based recommendations for the management of AS and RA. These efforts may serve disseminating the knowledge and increasing the current awareness among physicians who serve these patients. Also the implementation of these recommendations in daily clinical practice will increase with such efforts.

\section{ACKNOWLEDGEMENT}

We would like to thank for the time and interest of the Turkish physiatrists and rheumatologists participating in this study. We also thank to Dr. Ergun Ozdes, chief moderator of the e-mail list, for providing some of the e-mail addresses and also TLAR secretariat for the announcements.

\section{CONFLICT OF INTEREST}

Declared none.

\section{REFERENCES}

[1] Zochling J, van der Heijde D, Burgos-Vargas R, et al. ASAS/EULAR recommendations for the management of ankylosing spondylitis. Ann Rheum Dis 2006; 65: 442-52.

[2] Gossec L, Dougados M, Phillips C, et al. Dissemination and evaluation of the ASAS/EULAR recommendations for the management of ankylosing spondylitis: results of a study among 1507 rheumatologists. Ann Rheum Dis 2008; 67: 782-8.

[3] Kiltz U, van der Heijde D, Mielants $\mathrm{H}$, et al. ASAS/EULAR recommendations for the management of ankylosing spondylitis: the patient version. Ann Rheum Dis 2009; 68: 1381-6.

[4] Kiltz U, Feldtkeller E, Braun J. German patient version of the ASAS/EULAR recommendations for the management of ankylosing spondylitis. Z Rheumatol 2010; 69: 171-174, 176-9.

[5] Ozgocmen S, Duruoz MT. Turkish Translation and patient evaluation of the ASAS/EULAR recommendations-patient version for the management of ankylosing spondylitis. Turk $\mathrm{J}$ Rheumatol Turk Romatoloji Dergisi 2009; 24: 190-5.

[6] Bodur H, Sivas F, Yilmaz O, et al. Turkish league against rheumatism national recommendations for the management of ankylosing spondylitis. Turk J Rheumatol 2011;26: 173-86.

[7] Simon JA, Burgos-Vargas R. Agreement of Mexican rheumatologists with the Assessment in Ankylosing Spondylitis International Working Group and the European League against rheumatism recommendations for the management of ankylosing spondylitis. Ann Rheum Dis 2006; 65: 1535-6.

[8] Lavie F, Pavy S, Dernis E, et al. Pharmacotherapy (excluding biotherapies) for ankylosing spondylitis: development of recommendations for clinical practice based on published evidence and expert opinion. Joint Bone Spine 2007; 74: 346-52.

[9] Braun J, van den Berg R, Baraliakos X et al. 2010 update of the ASAS/EULAR recommendations for the management of ankylosing spondylitis. Ann Rheum Dis 2011; 70: 896-904.

[10] Schoels M, Aletaha D, Smolen JS, et al. Follow-up standards and treatment targets in rheumatoid arthritis: results of a questionnaire at the EULAR 2008. Ann Rheum Dis 2010; 69: 575-8.

[11] Smolen JS, Landewe R, Breedveld FC, et al. EULAR recommendations for the management of rheumatoid arthritis with synthetic and biological disease-modifying antirheumatic drugs. Ann Rheum Dis 2010; 69: 964-75.

[12] Ataman S, Borman P, Evcik D, et al. Management of rheumatoid arthritis: consensus recommendations from the Turkish league against rheumatism. Turk J Rheumatol 2011; 26: 273-94. 